\title{
Disputas epistemológicas e políticas entre imagens de Einstein: diferentes respostas acerca do valor da ciência e da universidade
}

\section{Epistemological and political disputes on Einstein's images: different answers for the value of science and of the university}

\begin{abstract}
Vinícius Carvalho da Silva
Programa de Pós Graduação em Filosofia - Universidade do Estado do Rio de Janeiro viniciusfilo@gmail.com
\end{abstract}

Recebido em 08/09/017

Aceito em 02/10/2017

\section{Resumo}

Como Einstein fazia ciência? Era um homem do laboratório ou um teórico puro? Foi mais influenciado pela busca da verdade ou pelo senso de utilidade? Como concebia a educação e a universidade? Tais questões que abordamos nesse trabalho têm como pano de fundo uma discussão mais ampla: Qual imagem de ciência que queremos reforçar? Como desejamos responder a questão: Qual o valor da ciência? Ao analisarmos como Peter Galison e Max Jammer compreendem a ciência de Einstein, esperamos iluminar, ainda que parcialmente, algumas destas questões. No entanto queremos mais do que comentar as respostas dos autores investigados. Buscamos oferecer nosso próprio entendimento acerca dos problemas levantados.

Palavras-chave: Teoria, Experimentação, Relatividade Especial, Relatividade Geral.

\section{Abstract}

how did Einstein do science? Was he a laboratory man or a pure theorist? Was he more influenced by the pursuit of truth or usefulness? How did Einstein conceive education and the university? Such questions that we approach in this paper have a broader discussion as background: What image of science do we want to strengthen? How do we 'want' to answer the question: What is the value of science? In looking at how Peter Galison and Max Jammer understand Einstein's science, we hope to illuminate, if only partially, some of these issues. However, we wish more than just to comment the answers of the investigated authors. We seek to offer our own understanding of the problems raised.

Keywords: Theory, Experimentation, Special Relativity, General Relativity, education, university. 


\section{Introdução: Verdade ou Utilidade?}

O que mais teria influenciado a pesquisa científica de Einstein? O ideal de busca da verdade, herdado de sua leitura dos filósofos ou o utilitarismo instrumentalista da Politécnica onde se formou? Como Einstein concebia a ciência? Como uma atividade intelectual que busca o conhecimento natural como um fim em si mesmo ou como um modo estratégico, um meio de obter conhecimentos com utilidade prática? O modo de trabalhar de Einstein, seu dia a dia de pesquisa, assemelhava-se mais ao dos filósofos naturais, absortos em suas especulações livres e envolvidos em profundas reflexões metafísicas, ou ao dos técnicos e homens práticos, que elaboram respostas objetivas e uteis para demandas concretas? Tais questões podem ser respondidas de modo tendencioso, ou unilateral, ou de modos mais arrojados e complexos. Talvez nem seja o caso de fazermos esses questionamentos, mas de elaborarmos outros, que sejam mais sofisticados. Por exemplo: O que queremos responder quando elaboramos uma narrativa sobre o modo como Einstein praticava ciência? Qual uso podemos fazer de uma imagem de Einstein?

Pensamos que Einstein é tomado, no imaginário popular como arquétipo do cientista. Ao falarmos como Einstein concebia e praticava ciência, estamos endossando uma imagem pública de pesquisa que responde a questão 'Qual é o valor da ciência?'. Assim, se dissermos que Einstein era um homem prático, um técnico, que elaborava as teorias a partir de analogias com máquinas, e as pensava como ferramentas úteis na resolução de problemas específicos, e que seu dia a dia era permeado por esse senso de utilidade, propalamos que o valor da ciência está em ser um meio (para a obtenção de soluções, produção de utilidades etc.), mas se dissermos que Einstein era um filósofo natural movido por uma inabalável paixão por compreensão e busca da verdade, endossamos o valor da ciência como um fim em si mesmo. Talvez as duas imagens opostas sejam caricaturais, incompletas, extremos que podem e devem ser evitados. Talvez a imagem que mais nos interesse seja a de um Einstein físico filósofo que buscava a verdade e apreciava a "utilidade do inútil" sem negar a importância da técnica e da tecnologia para o bem estar humano; alguém que buscava a expansão conceitual dos limites do conhecimento científico fundamental, mas que ao mesmo tempo era um ator social de carne e osso, e que, portanto, afetava e era afetado pela dimensão social e política de seu cotidiano e não somente por pressupostos metafísicos e ideais filosóficos. Nas próximas páginas veremos como Peter Galison e Max Jammer elaboraram suas imagens de Einstein, e porque devemos buscar uma imagem mais complexa.

Quando escolhemos um instrumento, selecionamos também o tipo de imagem que desejamos obter. Microscópios observam os componentes diminutos de uma estrutura, abrem os espaços fechados. Telescópios se dirigem para a vastidão dos espaços abertos. Neste trabalho tomamos tais instrumentos como símbolos dessas duas tendências que percorrem caminhos em direções contrárias. Podemos lembrar também do famoso painel de Rafaelo "A Escola de Atenas", em que Aristóteles aponta para a terra, enquanto Platão para os céus. As imagens de Einstein obtidas pelo "microscópio social" focalizam, e aumentam diversas vezes, a importância dos elementos sociais e políticos em sua teoria física, subestimando elementos teóricos e metafísicos, ao passo que as imagens obtidas por "telescópios metafísicos" tendem a perder toda a riqueza microscópica do mundo a nossa volta, superestimando a importância dos fatores filosóficos e teóricos. Em estudos de ciências o ideal é que busquemos uma abordagem mais complexa, capaz de trabalhar e conjugar, de modo plural, todos os inúmeros fatores que influenciam as práticas científicas.

\section{Os microscópios de Galison}

O físico e historiador da ciência Peter Galison é um dos principais nomes dos chamados science studies. De acordo com André Luís de Oliveira Mendonça, em Filosofia da ciência e science studies: a guerra pela paz, essa área de investigação da ciência busca compreender como a ciência "realmente é praticada", sendo uma atividade interdisciplinar, que analisa os aspectos políticos, históricos, sociais, institucionais e epistêmicos da ciência (MENDONÇA. 2012, p. 167-179). Os science studies se destacam por considerar a presença de elementos na pesquisa científica que eram avaliados como externos e irrelevantes pela filosofia da ciência

1 ORDINE, Nuccio. A utilidade do inútil - um manifesto. Luiz Carlos Bombassaro (Trad.). Rio de Janeiro: Zahar, 2016. 
tradicional (REIS; VIDEIRA. 2013, p. 584). As características principais da concepção de ciência dos science studies são o foco na prática experimental e, consequentemente, a assunção do laboratório como $o$ lugar da ciência. A atitude fundamental dos Science Studies fica clara no artigo A Filosofia da Ciência sob o signo dos Science Studies, de Antonio Augusto Passos Videira: "a ciência não se reduz à produção de teorias, mas também abrange com igual relevância as dimensões da experimentação e instrumentação" (VIDEIRA. 2005, p. 77).

Uma crítica que buscaremos empreender neste trabalho é que Galison, em sua narrativa da ciência de Einstein, parece não destacar com o mesmo cuidado e rigor, "com igual relevância", a importância dos fatores teóricos e da prática experimental, dos aspectos sociais e culturais, do trabalho laboratorial diário, dos estudos e ideias filosóficas, na formação do Einstein da relatividade restrita. Ao lermos Os relógios de Einstein, em Os Relógios de Einstein e os mapas de Poincaré, não verificamos a mesma ênfase na importância das práticas e vivências teóricas e experimentais por um lado, e do dia a dia do trabalho laboratorial em Berna, por outro, na ciência de Einstein, tampouco constatamos que Galison privilegia os aspectos epistêmicos tanto quanto os institucionais, sociais e políticos. Entre os fatores elencados, parece haver uma assimetria. Tal assimetria, ao subestimar alguns fatores e superestimar outros, compromete a complexidade da imagem obtida.

O Einstein de Galison é fundamentalmente um homem de laboratório, um técnico do escritório de patentes de Berna, um profissional decisivamente influenciado pelo mundo das máquinas, pelo contato com engrenagens, relógios e demais equipamentos laboratoriais.

O Einstein de Galison não pensa que a teoria é que decide o que observamos. Ele chega aos principais conceitos de sua teoria inspirado pelo trabalho cotidiano no laboratório suíço. Aqui, não há igualdade entre teoria e prática experimental, entre o gabinete onde se especula livremente e o laboratório pleno de máquinas, ferramentas, instrumentos de medição. Ao final da leitura, temos a impressão de termos conhecido outro Einstein que não aquele que conhecemos lendo seus escritos autobiográficos e filosóficos. Não estamos mais diante do físico filósofo e de suas poderosas conjecturas metafísicas, mas de um físico-engenheiro, experimental e prático, imerso no mundo da medição e das patentes.

Nesta mesma obra, Galison narra que por ocasião do centenário de nascimento de Einstein, a imagem da física difundida era a de que, no último século, tal ciência havia se desenvolvido por meio de investigações em teoria pura. Sua discordância desta visão, e com relação especificamente a Einstein, residia no fato de que este não lhe parecia o físico puramente teórico que "todos" narravam, mas também um homem prático, do mundo das patentes, imerso no "universo material da tecnologia científica" (GALISON. 1999, p. 396). O Einstein de Galison não somente não partia da teoria para a experiência, como fazia uma operação oposta radical: Partia do mundo das máquinas, da tecnologia, do laboratório de patentes para a construção teórica, por meio de poderosas analogias entre as máquinas presentes em seu ambiente de trabalho e os conceitos fundamentais das teorias ainda em gestação em sua mente:

o girocompasso conduziu diretamente e demonstravelmente Einstein a uma imagem da estrutura atômica e a uma teoria do ferromagnetismo na qual o átomo, num sentido assaz específico, se tornou num girocompasso com o elétron orbital de Lorentz como elemento rotatório (GALISON. 1999, p. 396) .

A teoria física seria elaborada por esse processo analógico, que não é bem um método, mas um fenômeno psicológico. O físico é influenciado por seu ambiente social, por seu dia a dia de trabalho, e consequentemente, tal influência estaria presente na construção da teoria. No caso de Einstein, isso significava observar o funcionamento das máquinas e em seguida conceber uma imagem da natureza que espelharia tal engenharia.

De acordo com Galison em Os relógios de Einstein, existem muitos e bons motivos para desconstruirmos a imagem de Einstein como o "mais etéreo dos físicos", e o pensarmos como um cientista de laboratório, que buscou no mundo das máquinas algumas das ideias mais importantes de suas teorias. Em Culturas etéreas e culturas materiais, Galison deixa sua posição muito clara, ao atacar o que chamou de theorocentrism, uma ênfase descabida dada à teoria, no século XX, tanto porque a relatividade e a mecânica quântica tiveram um 
grande impacto cultural, quanto porque filósofos da ciência tais como Thomas Kuhn e Russell Hanson, entre outros, se empenharam, de modo persuasivo e com elevada "excitação filosófica", em enaltecer o papel da teoria na ciência (GALISON. 1999, p. 395)².

Em Berna, onde Einstein morou por alguns anos, a temática do tempo e de sua medição era algo muito presente. Berna ostentava muitos relógios públicos e foi a primeira cidade a tê-los sincronizados. A necessidade de sincronizar os relógios para a obtenção de horários simultâneos em localidades diferentes era política e pragmática (GALISON. 2005, p. 229). O conceito de simultaneidade que era fundamental em tal temática, viria a ser igualmente fundamental na relatividade restrita de Einstein. Galison propõe, portanto, uma clara influência entre o meio social e cultural, a configuração urbana da Berna em que Einstein vivia e a elaboração dos conceitos essenciais de suas teorias de 1905.

Outra influência forte teria sido dada por sua formação. O utilitarismo prático ligado aos conhecimentos em Engenharia era o foco acadêmico da ETH, na qual Einstein se formou: "Desde o início (e ao longo de toda a história) o aplicado e o abstrato entraram juntos na ETH” (GALISON. 2005, p. 231). Galison tenta dar corpo ao seguinte argumento: Einstein não foi treinado academicamente para valorizar a teoria pura, mas para amalgamar abstração e aplicação. Este argumento se baseia na convicção de Galison de que o pensamento de Einstein não revela apenas matizes pessoais, mas também institucionais. Um terceiro fator preponderante para que Einstein se tornasse o físico concebido por Galison teria sido seu trabalho como técnico perito no escritório de patentes de Berna: "Ao longo dos seus anos em Berna, o trabalho e o pensamento de Einstein foram totalmente impregnados pelos princípios materializados das máquinas" (GALISON. 2005, p. 231). A tese forte de Galison é que o contato profissional de Einstein com o laboratório de patentes, aquele ambiente institucional repleto de engrenagens, instrumentos e máquinas, teria influenciado o físico alemão de modo fundamental. "Durante os anos de Einstein nas patentes (Junho de 1902 a Outubro de 1909) rodeavam-no máquinas de todas as espécies” (GALISON. 2005, p. 251).

O laboratório de Berna teria sido, literalmente, a fonte da juventude de Einstein, onde ele teria ido buscar não somente as imagens fulcrais para a elaboração de poderosas analogias entre o funcionamento das máquinas e o funcionamento do mundo, como também um "modo" específico de trabalhar que se revelaria, inclusive, na forma como ele escreveria seus artigos científicos; quanto a apresentação, mais parecidos com registros de patentes do que com artigos científicos propriamente ditos. De acordo com Galison, não é o caso que o ambiente de trabalho exerceu, apenas, alguma influência sobre Einstein. A influência foi realmente decisiva. Dois fatos chamam mais a atenção. A influência dos relógios sincronizados na construção do conceito de simultaneidade na relatividade e a influência dos giroscópios na elaboração de sua teoria do átomo:

Significativamente, a bússula giroscópia serviu de maneira muito clara como modelo para a teoria do átomo magnético de Einstein. (...) A tecnologia das patentes e a interpretação teórica estavam mais próximas do que teria podido parecer (GALISON. 2005, p. 253).

Galison buscou desconstruir a imagem de Einstein como filósofo natural, o mais "etéreo dos físicos", ou físico filósofo envolvido pela teoria pura, e no seu lugar erguer a imagem de "Einstein cientista-funcionário do departamento de patentes", homem atento ao mundo das máquinas e das engrenagens, movido por esse senso prático, um engenheiro de escalas cósmicas, que elabora sua teoria física por analogia com as invenções tecnológicas de seu tempo (GALISON. 2005, p. 257).

A quem interessa a imagem de Einstein apresentada por Galison? Qual tipo de educação científica, de formação universitária, de instituição de ensino e pesquisa, de política científica pode se beneficiar deste Einstein? Ao recontarmos a história de Einstein nestes termos, qual modo de se fazer ciência se privilegiará? Como respondemos as perguntas "para quê ciência?" e "Qual o valor da ciência?" tendo este Einstein de Galison como referencial? A nosso ver, esta imagem de Einstein pode reforçar o status quo da tecnociência e legitimar a pedagogia utilitarista e instrumentalista, a noção de que a universidade deve se fundar na

2 GALISON. Culturas Etéreas e Culturas Materiais in A Ciência tal qual se faz. Lisboa: Edições José Sá da Costa. 1999. 
especialização técnica, no senso de utilidade prática, buscando reduzir, ou quiçá eliminar, a importância da especulação pura, da filosofia e da metafísica como força de orientação para a ciência. A relatividade já não seria uma poderosa criação teórica, mas uma máquina, ainda que abstrata; um projeto de engenharia. Galison o diz com todas as palavras: "Einstein construíra a sua máquina abstrata da relatividade a partir de um mundo material de relógios sincronizados” (GALISON. 2005, p. 295).

No entanto, Heisenberg teria questionado Einstein acerca da relação entre os fatos da experiência e a construção das teorias, lembrando-o que na relatividade o tempo é entendido como aquilo que pode ser medido por relógios, ou seja, por “magnitudes observáveis". Deste modo, um instrumento prático da experiência diária, o relógio, exerceria uma importante função na constituição da teoria. A resposta de Einstein foi categórica: "Isso é bobagem (...). Na realidade, acontece exatamente o oposto. É a teoria que decide o que observamos" (BRIAN.1998, p. 174).

Temos que reconhecer que não é nada trivial um instrumento, como o relógio, aparecer numa teoria como um conceito fundamental, como ocorre na relatividade, o que fica claro no trabalho Sobre a eletrodinâmica dos corpos em movimento (EINSTEIN, 1905), e em tantos outros trabalhos de Einstein. Todavia, não estamos certos de como podemos responder uma questão aparentemente muito simples. O que é um relógio? Principalmente, no escopo da física. A materialização mais grosseira - quer dizer, mais evidente - do conceito de relógio é o relógio como instrumento mecânico, fabricado pelo homem, de uso diário, como os relógios de Berna. Temos aí, o relógio como máquina. Mas podemos pensar o relógio como evento natural, ou processo físico. Temos então a contagem das oscilações de um átomo, a mensuração dos pulsos de radiação emitidos por estrelas, entre outros exemplos. Sabemos que Einstein foi grande admirador e leitor de Maxwell, e que este, como nos diz em sua Teoria das Moléculas, calculou a taxa média de colisões por segundo das moléculas de um gás (MAXWELL. 2017, p. 59). Não nos é difícil imaginar que na cabeça de um físico engenhoso tal média possa servir como um relógio, pois se ele imagina que em um determinado gás as moléculas colidiram $x$ vezes, ele pode calcular quantos segundos se passaram. Ele pode medir a passagem do tempo com base na quantidade de colisões, embora a operação de senso comum seja a inversa. Ou seja, é por saber quantos segundos se passaram que poderíamos deduzir a quantidade de colisões. O que os relógios como máquinas e os relógios como eventos tem em comum, é que ambos expressam uma regularidade, demarcam pequenos ciclos; é possível medir e sincronizar eventos cíclicos, e, de acordo com Einstein, é possível definir o tempo como aquilo que é medido desta forma, seja pelos relógios da velha Berna, seja pelas oscilações de um átomo solitário. Quando pomos as coisas nestes termos, parece que reduzimos a influência do relógio como máquina na teoria, e enaltecemos a ideia abstrata de medição de eventos cíclicos que a ele se liga.

Em nossa concepção, ao sustentar que Einstein não era somente um teórico, como também um homem prático de laboratório, Galison exagera nas tintas e pinta um Einstein que foi acima de tudo um físico-engenheiro de laboratório, apesar de ter sido também um físico-filósofo teórico. Assim ele maximiza a importância dos aspectos sociais enquanto minimiza a participação dos fatores teóricos e filosóficos, criando aquela assimetria da qual já falamos.

Uma abordagem mais complexa e menos assimétrica seria considerar tanto os fatores sociais, políticos e institucionais, cotidianos e locais, quanto os compromissos metafísicos, axiológicos, ideológicos, as filiações filosóficas e os ideais teóricos. Terá Galison, para se livrar de uma imagem teorocêntrica de Einstein, ido de um extremo ao outro, perdendo assim toda a riqueza das complexas gradações que se situam a meio caminho entre polos contrários?

\section{Os telescópios de Jammer}

Enquanto a visão de Galison se projeta para os espaços sociais, a do físico Max Jammer se dirige para as alturas etéreas da metafísica e da teologia. De uma leitura cuidadosa de Galison e de Jammer, logo se vê que suas conclusões são diametralmente opostas. Galison enfatiza a importância do laboratório, do trabalho diário, a influência do mundo das máquinas e da prática experimental na elaboração da teoria da relativida- 
de. Aventa que o senso prático da Politécnica, que evitava a teoria pura e mesclava teoria e aplicação, pode ter sido um fator importante no modo como Einstein praticava ciência. Já Jammer não poderá admitir que a relatividade tenha recebido influências externas à física teórica, a não ser que tenham vindo da filosofia e da religião:

\begin{abstract}
Se tivesse havido tais ingredientes extrafísicos na construção einsteiniana da Teoria da Relatividade, eles não poderiam ter sido sociológicos ou políticos - como afirmou Feuer, por exemplo - mas somente filosóficos ou religiosos, talvez, no sentido da definição einsteiniana desse termo (JAMMER. 2013, p 33).
\end{abstract}

Aqui temos uma diferença gritante entre Galison e Jammer. Para Jammer, não entenderemos o pensamento de Einstein apelando para aspectos sociológicos e políticos, institucionais, mas considerando suas reflexões filosóficas e teológicas. O Einstein de Jammer conquista aos poucos algumas importantes parcelas do real a partir de seus esforços teóricos, da especulação livre e do pensamento puro, de suas investigações conceituais dos fundamentos da física, motivado por seus estudos filosóficos, por suas leituras e conversas com os amigos da Academie Olympia, e por seus profundos sentimentos religiosos. Enfim, o que essa imagem reforça é a ideia de que um dos maiores cientistas da física contemporânea, pioneiro tanto da relatividade quanto da mecânica quântica, era um filósofo natural, ou ao menos um "físico filósofo", compromissado com fortes pressupostos metafísicos e princípios axiológicos, e jamais um técnico de laboratório movido pelo senso de utilidade, que elabora sua teoria física por analogia com a mecânica das máquinas.

De acordo com Jammer, esse físico-filósofo teria, entre as teorias da relatividade restrita e geral, passado do empirismo ao racionalismo: "Como resultado de seu trabalho sobre a Relatividade Geral, Einstein havia recuado de sua adesão ao positivismo de Mach, passando a adotar um realismo racional" (JAMMER. 2013, p. 44). O que significa dizer que Einstein era realista e racionalista? A resposta para tal questão é dada pelo fato de que Einstein concebia o mundo como uma realidade ordenada e objetiva, independente do sujeito do conhecimento. Todavia, o sujeito do conhecimento seria capaz de, por meio da teoria pura, compreender paulatinamente este real. De acordo com Jammer, Einstein "via a física como 'uma tentativa de apreender a realidade tal como é pensada, independentemente de ser observada"” (JAMMER. 2013, p. 169).

Para o Einstein de Jammer, a filosofia não é um mero interesse pessoal, tampouco algo trivial. A filosofia de Baruch Espinosa influencia o físico teórico de modo profundo. Para fundamentar sua visão, Jammer cita uma carta de Einstein a E. Büsching, de 25 de outubro de 1929: "Nós, seguidores de Espinosa, vemos nosso Deus na maravilhosa ordem e submissão às leis de tudo o que existe (...)" (JAMMER. 2013, 42). Einstein, já não o jovem do laboratório de patentes de Berna, de 1900, tampouco o leitor voraz de Mach, da Akademie Olympia, mas sim o físico teórico de 1929, se declara um seguidor de uma dada metafísica. Na realidade, são abundantes na literatura de Einstein passagens nas quais ele deixa claro que é um adepto da filosofia de Espinosa. Em resposta ao rabino Herbert S. Goldstein, o físico teórico declarou: "Acredito no Deus de Espinosa, que se revela na harmonia ordeira daquilo que existe (...)" (JAMMER. 2013, p. 40). O Einstein de Galison seria o da juventude, e o de Jammer o da maturidade, por isso ambos podem ter razão ao mesmo tempo. Todavia, para que isso seja o caso, a mudança entre uma fase e outra tem de ser extremamente radical. Não pensamos que o Einstein da maturidade concordasse com a narrativa de Galison sobre sua juventude.

Não é somente em cartas e conversas informais que Einstein declarava seu espinosismo. Nos textos Religião e Ciência e Religiosidade da Pesquisa sua posição fica evidente. Seu próprio trabalho científico estaria impregnado de tal metafísica. A começar por seu determinismo forte e por sua inabalável convicção na racionalidade do mundo: "Einstein foi mais influenciado pela tese espinosista de um determinismo irrestrito e pela crença na existência de uma inteligência superior, que se revela na harmonia e na beleza da natureza" (JAMMER. 2013, p. 39). Jammer questiona se Einstein também não teria sido influenciado pela filosofia de Espinosa na busca por uma teoria do campo unificado: 
Esses sentimentos [de religiosidade espinosista] decerto motivaram também sua incansável tenacidade na busca de uma teoria de campo unificada, tarefa na qual embarcou logo após a conclusão de sua Teoria Geral [relatividade geral]. (...) É bem possível que essa crença tenha-se enraizado em sua convicção espinosista da unidade da natureza (JAMMER. 2013, p. 46).

A filosofia de Espinosa, de acordo com Jammer, pode ter sido importante para Einstein também na elaboração de uma constante cosmológica, uma hipótese ad hoc a partir da qual poderia deduzir um universo estático da relatividade geral: "Houve quem sugerisse que ele tivesse cometido esse erro crasso [elaborar a constante cosmológica] por ter sido influenciado por Espinosa, que havia declarado em sua Ética que Deus é imutável" (JAMMER. 2013, p. 50). Jammer considera tal questão desconcertante e em aberto: “É bem possível que a motivação para introduzir a constante cosmológica tenha sido o resultado direto da influência espinosista" (JAMMER. 2013, p. 114). A constante cosmológica evita que da relatividade geral seja deduzido um universo dinâmico. Espinosa, na Ética, corolário 2 da proposição 20, parte I, sustenta que "Deus é imutável", ou seja, que o universo é imutável, logo, não poderia ser dinâmico (ESPINOSA. 1957, p 38).

O Einstein de Galison teria tido no laboratório a grande influência de seu trabalho científico. O Einstein de Jammer é um matemático puro, um metafísico racionalista adepto de Espinosa que talvez tenha feito suas grandes conjecturas científicas motivado por razões de ordem filosófica. Cada qual corresponderia a uma fase de sua vida. Serão estes Einstein's incomensuráveis? Isto é, "As imagens de ciência, dos valores na ciência e do valor da ciência, obtidas de cada Einstein, seriam imagens discordantes?”.

\section{Superando as imagens dicotômicas: por uma abordagem complexa em filosofia da ciência}

Diversos são os filósofos, historiadores, sociólogos e demais estudiosos que escreveram sobre a vida e a obra de Einstein. As narrativas são plurais, variadas e bastante discordantes. Quais estudos são corretos? Quais refletem realmente quem foi Einstein? Ora, um caminho natural seria abordar Einstein por ele mesmo, uma vez em que este escreveu muito sobre suas concepções, trocou centenas de correspondências, concedeu entrevistas e ministrou palestras e seminários, proferiu discursos. No entanto, aqueles que escreverem sua versão de Einstein dirão que também consultaram diretamente tais fontes, e cada um reclamará como sua a imagem legítima de Einstein. Neste trabalho assumimos que em história da ciência não cabe contar como as coisas realmente aconteceram, ou quem foi, o que pensava e como agia determinado personagem. O passado não pode ser plenamente desvelado, mas apenas parcialmente apreendido. $\mathrm{O}$ mesmo personagem pode ser apropriado por diferentes tradições, suas declarações e práticas podem ser interpretadas e utilizadas por estudiosos com pressupostos, filiações e interesses distintos. Digamos que o passado pode ser recontado, que podemos elaborar boas representações do passado, e que quanto mais complexas forem tais representações, maiores as nossas chances de que sejam próximas do passado real. Por outro lado, sem compromisso com o real ou a verdade, o passado também pode ser instrumentalizado. Isto é, diferentes imagens do passado podem ter usos políticos pontuais conforme interesses específicos. Einstein, por exemplo, serve como um arquétipo, um porta-voz, ou de maneira mais vulgar, como o grande garoto propaganda da ciência. Ao dizermos que ele pensava e praticava a ciência de um modo X, reforçamos publicamente a imagem X de ciência, buscamos legitimá-la e apresentá-la como a imagem vencedora e a mais prolífica. Por isso concebemos que cada autor que escreveu sobre Einstein não detém a palavra final, tendo elaborado uma imagem de Einstein, dentre tantas possíveis. Nem todas as imagens merecem crédito. Não estamos em seara relativista como se o tribunal do real não existisse. Algumas imagens podem não resistir a mais simples pesquisa documental, assim como algumas teorias ou hipóteses em física teórica podem se desvanecer diante do mais ínfimo contato experimental com a natureza. Não podemos prescindir do real, e o real impõe limites. No entanto, muitas imagens robustas, complexas, podem coexistir e disputar. A disputa não é somente epistêmica, filosófica, mas é também axiológica, ideológica e política. 
Entre diferentes narrativas sobre as realizações de Einstein, como as de Galison e de Jammer, o que está em disputa não é (ou não é somente) a verdade sobre a vida de Einstein, mas duas imagens diferentes de ciência; uma que valoriza as práticas cotidianas e a influência da base material, da localidade, na produção do pensamento, e outra que coloca em destaque os pressupostos metafísicos, os valores epistêmicos e os compromissos teóricos. O Einstein de Galison é o cientista técnico e prático do mundo das máquinas, ao passo que o Einstein de Jammer é o filósofo natural teórico das livres criações do espírito. As escolhas são arbitrárias, mas coerentes com seus objetivos. Ao escolher seus referenciais desta forma, Galison pode falar de um homem prático influenciado pelo clima cultural da Politécnica e pelo trabalho no laboratório de patentes, e Jammer pode falar de um físico teórico racionalista fortemente motivado por razões filosóficas e teológicas. O erro de cada qual está em não deixar claro que seu Einstein é uma imagem de Einstein, e sugerir que seja o Einstein, verdadeiro, único e definitivo.

Ao criarmos narrativas caricaturescas de Einstein, ou selecionarmos uma imagem incompleta ou outra, não reconhecemos a complexidade epistemológica, histórica e cultural que engendrou a física relativística. É preciso enfatizar que as concepções de ciência subjacentes a cada imagem reforçam diferentes entendimentos referentes à política científica, instituições e modelos de pesquisa, educação e divulgação de ciência. Diferentes imagens de Einstein podem ser estrategicamente instrumentalizadas para difundir uma ou outra concepção de ciência, com valores distintos, que suporta, por sua vez, políticas e práticas científicas e institucionais específicas.

Quais serão os impactos de cada imagem de Einstein na formação intelectual e profissional de um jovem estudante de ciências? Como tais visões poderão perturbá-lo e influenciá-lo? Como cada contato o ajudará a elaborar respostas diferentes para as mesmas questões: Qual o valor da ciência? Por que devo ser cientista? Qual a melhor maneira de se fazer ciência? Na cabeça de nosso jovem, esta última pergunta assume outra formulação: Como Einstein fazia ciência?

O Einstein de Galison endossará a imagem do cientista contemporâneo, do técnico de laboratório, do praticante de tecnociência, corroborando a imagem da ciência atualmente praticada pelos grandes centros de produção do conhecimento e reduzindo o teórico livre ao prático bem-sucedido. Enfim, é uma personificação do cientista do status quo. O Einstein de Jammer, por sua vez, reforçará a imagem de um filósofo natural, imerso em sua solidão metafísica, compromissado com doutrinas fortes de filosofia e envolvido profundamente por emoções religiosas. Se levarmos as duas imagens às últimas consequências, Galison nos dará um físico-engenheiro que constrói suas teorias por analogia com as engrenagens das máquinas que observa, enquanto Jammer oferecerá um físico-téologo cuja filosofia natural é parte de seu esforço por compreender os pensamentos de Deus.

Concordamos com Galison quanto à importância de se considerar fatores políticos, institucionais, sociais, cotidianos, no processo de produção de conhecimento, mas não cremos que estes fatores possam explicar, por si mesmos, a complexidade da prática científica, que apesar de estar atravessada por muitos aspectos diferentes, é uma atividade peculiar, influenciada por pressupostos epistêmicos intrínsecos - pressupostos metafísicos - e princípios axiológicos (SILVA, 2015) . $^{3}$

A imagem do Einstein de Jammer é bela e atraente, e poderia ser o cânone normativo de como deveriam ser os cientistas naturais - e por isso mesmo nos parece tão fascinante, frágil, incompleta e irreal quanto uma lenda pode ser. Concordamos com Jammer quanto ao fato de Einstein ser um físico-filósofo cujos acertos, e também os fracassos, são resultados, sobretudo, de seus esforços teóricos, de seu trabalho de revisão conceitual dos fundamentos da física e de suas convicções filosóficas. Acreditamos, em primeiro lugar, que o ideal de cientista como homem de alta cultura, ciente dos problemas epistemológicos, ontológicos e axiológicos de sua pesquisa, é fundamental para que a ciência possa ser algo mais do que uma tecnociência utilitarista e instrumentalista. Todavia, falta à imagem de Jammer aquilo que sobra na imagem de Galison; a consideração de como os aspectos sociais exercem real influência na produção do conhecimento científico. 
A ideia de abordagem complexa que propomos neste trabalho não possui outra intenção a não ser salientar uma imagem de ciência que embora se funde em pressupostos epistêmicos intrínsecos, é composta também por fatores sociais, culturais e políticos. A teoria física possui pressupostos metafísicos e é fruto de uma comunidade que partilha princípios axiológicos, mas não é exclusiva dos espaços abstratos e etéreos do pensamento puro; ela ocorre no mundo e trata deste. Não poderia, portanto, estar imune aos seus vapores. Sendo assim, o modo como concebemos a ciência, o seu valor, e a imagem que fazemos dos cientistas e da teoria física, possui importância não somente epistêmica, teórica, como também axiológica, política, institucional e pedagógica, sendo posicional; quando respondemos o que é a ciência, qual o valor da investigação científica, o que é a teoria física e como os cientistas as elaboram, estamos posicionando a ciência no mundo e pontuando qual espaço ela deve ocupar na sociedade e na cultura.

Pensamos que é não somente possível, como necessário superar qualquer dicotomia entre (A) a busca pelo entendimento da dimensão social e política da ciência, por um lado, e (B) a compreensão de sua base metafísica, axiológica, enfim, filosófica, por outro. Parece que Galison e Jammer pensam que a adoção de uma abordagem elimina a outra, como se A e B fossem autoexcludentes. Propomos que uma imagem mais sofisticada é obtida quando todas as dimensões são igualmente exploradas. Nenhuma imagem extrema de ciência nos interessa. Não é necessária uma anemia filosófica para ressaltar os aspectos sociais, tampouco é desejável uma hipertrofia metafísica que não os leve em conta. Podemos investigar como todas estas dimensões - filosófica, cultural, ideológica, psicológica, social e política -, se interpenetram no caso concreto, e como múltiplos fatores desempenham funções variadas na produção do conhecimento científico. A imagem de ciência que desejamos é epistemicamente centrada e socialmente robusta, isto é, leva em conta tanto a importância dos pressupostos metafísicos, dos compromissos filosóficos e teóricos, dos valores culturais e morais, quanto dos fatores sociais e políticos, do cotidiano, da localidade. A imagem ideal que concebemos de Einstein é aquela que responde que o valor da ciência é filosófico, cultural, social e político, ao mesmo tempo. Verdade e utilidade não se excluem, principalmente se valorizarmos a "utilidade do inútil", se entendermos que além da utilidade prática, comercial, tangível, há a utilidade intangível do patrimônio cultural da humanidade, e que sua preservação, transmissão e desenvolvimento é o que cabe à educação, tanto nas escolas quanto nas universidades.

A imagem pluralista e complexa de Einstein que privilegiamos é corroborada pelo próprio. Einstein considerava que "a ciência sem epistemologia - na medida em que tal seja imaginável - é primitiva e confusa" (EINSTEIN, apud PAIS. 1995, 12-13). O cientista não pode deixar de adotar uma epistemologia, sob a pena de desenvolver um trabalho "primitivo." Mas qual epistemologia adotar? É na resposta a tal pergunta que Einstein revela seu pluralismo forte; o cientista deve adotar a epistemologia que melhor lhe servir! Sem "escrúpulos", não deve se furtar em adotar diferentes sistemas epistemológicos conforme as necessidades epistêmicas de seu trabalho:

Ele [o cientista] deve parecer ao epistemólogo sistemático como um tipo de oportunista sem escrúpulos: revela-se realista, na medida em que tenta descrever um mundo independente dos atos de percepção, idealista, na medida em que vê os conceitos e teorias como invenções livres do espírito humano (não deriváveis logicamente do que é dado empiricamente); positivista, na medida em que considera seus conceitos e teorias justificados somente enquanto proporcionam uma representação lógica das relações entre experiências sensoriais. Pode mesmo parecer platônico ou pitagórico, na medida em que considera o ponto de vista da simplicidade lógica como uma ferramenta indispensável e efetiva de investigação (EINSTEIN, apud PAIS. 1995, 13).

Ao privilegiarmos um Einstein somente "empirista-homem de laboratório" ou "racionalista-espinosista", perderemos a riqueza desta imagem plural multifacetada, do cientista que sem "escrúpulos" sabe reconhecer a complexidade epistemológica de sua atividade. 


\section{Como Einstein pensava a Universidade?}

Outra maneira de perguntar "Qual imagem de ciência é mais fecunda?” - e não se pode levantar tal questão sem perguntar "Para quem tal imagem é a mais fecunda, e por quê?" - é propondo outra análise. Para Einstein, qual é o valor da universidade? Como o físico filósofo pensava a relação entre ciência e universidade? Será a universidade um espaço de formação profissionalizante, técnica, voltado para fins práticos, permeado por uma noção instrumental de utilidade, ou será um centro de formação cultural ampla, tendo o desinteresse, a liberdade e a criatividade como valores fundamentais?

Peter Galison pensou em três fatores sociais que teriam impactado o modo como Einstein praticava ciência, influenciando o conteúdo de seu trabalho como físico teórico: (1) Seu dia a dia como cidadão em Berna, uma cidade cheia de relógios, instrumentos de medição e sincronização, (2) A influência do ambiente utilitário e técnico da Politécnica de Zurique, o ETH, e (3) Seu cotidiano como funcionário do escritório de patentes de Berna, em um ambiente repleto de máquinas, mecanismos, instrumentos, engrenagens, etc. Vamos nos ater ao ponto 2. Terá o ambiente utilitário da Politécnica sido decisivo na formação do caráter intelectual de Einstein a ponto de orientar a construção de sua teoria física? De acordo com Galison o ambiente acadêmico da ETH era marcado por um utilitarismo prático, próprio de uma escola de engenheiros e técnicos. Na ETH não havia espaço para a livre especulação e o desenvolvimento da teoria pura. A Politécnica não seria, assim, uma Universidade, em sentido amplo, ou seja, não seria propriamente um espaço marcado pelo ideal de formação pela ciência, Bildung, mas uma escola técnica e profissionalizante. A dimensão da aplicação estava sempre presente (GALISON. 2005, p. 231). A formação em tal ambiente seria uma das principais influências sobre o modo de trabalhar de Einstein.

Se tal influência ocorreu, no entanto, nos parece que ela só poderia ter sido ou inconsciente ou negativa, e não positiva, como Galison propõe. Afirmar que foi inconsciente nos custaria uma ampla pesquisa em psicologia da ciência, e há razões substantivas para pensarmos que foi negativa. Isto é, o ambiente da ETH dizia a Einstein o que não fazer, como não proceder, que tipo de imagem de ciência não deveria ser cultivada, que tipo de ambiente acadêmico não deveria ser privilegiado. Essa reação negativa aos anos de formação são evidentes em sua autobiografia científica, quando, ao lembrar-se da juventude na ETH o físico filósofo afirmou:

O problema era que, como estudantes, éramos obrigados a acumular essas noções [noções fundamentais dos vários campos da física] em nossas mentes para os exames. Esse tipo de coerção tinha (para mim) um efeito frustrante. Depois de ter passado nos exames finais, passei um ano inteiro durante o qual qualquer consideração sobre problemas científicos me era extremamente desagradável. Porém, devo dizer que na Suíça essa coerção era bem mais branda do que em outros países, onde a verdadeira criação científica é completamente sufocada. (...) Na verdade é quase um milagre que os métodos modernos de instrução não tenham exterminado completamente a sagrada sede de saber, pois essa planta frágil da curiosidade científica necessita, além de estímulo, especialmente de liberdade; sem ela, fenece e morre. É um grave erro supor que a satisfação de observar e pesquisar pode ser promovida por meio da coerção e da noção de dever (EINSTEIN. 1982, p. 25-26).

Essa passagem revela muito do que Einstein pensava sobre a universidade. Em primeiro lugar, constatamos uma severa crítica ao ambiente universitário de muitos países, capaz de "sufocar" a "verdadeira criação científica". Esse ambiente coercitivo, que cobra produção e bom desempenho em exames, restringiria a liberdade de pesquisa, indispensável para o florescimento da ciência. Argumentamos que há elementos suficientes em tal passagem para afirmarmos que Einstein pensava que o ambiente universitário deveria fomentar a pesquisa científica desinteressada, a mais livre possível, e não uma pesquisa pautada por interesses utilitários, metas de produção, exames rígidos. Somente em um ambiente de liberdade, a curiosidade intelectual poderia promover as conquistas mais criativas. Embora a Suíça não reproduzisse os piores exemplos, não estava a salvo de tal tendência. 
Conforme Medeiros e Medeiros em Einstein e a Educação, ao entrar na ETH o jovem estudante sonhava com uma educação liberal e criativa, mas cedo se desencantou e percebeu que este não era o caso (MEDEIROS \& MEDEIROS. 2006, p. 40). O sistema de exames da ETH, embora não sendo um dos mais ortodoxos, marcou profundamente Einstein, que chegou a comparar o ambiente universitário ao "sistema penal" (MEDEIROS \& MEDEIROS. 2006, p. 44). Além disso, sua formação curricular era mais adequada a um engenheiro do que a um físico teórico. Sua insatisfação com isto era tão grande que Einstein tornou-se um aluno faltante crônico, comparecendo a poucas aulas, além de ter diversos problemas de relacionamento com muitos professores. Einstein compensava sua formação estudando por conta própria a obra de diversos físicos e filósofos.

Os problemas de Einstein com a formação na Politécnica não podem ser minimizados como uma mera incompatibilidade de gênios ou uma questão pessoal. O que o físico filósofo viria a concluir é que tal tipo de vida acadêmica era coercitiva, maçante, sufocante e contraproducente. $\mathrm{O}$ espírito científico não é formado pela urgência em atender demandas práticas, nem pela disciplina "penal", mas por uma espécie de paixão que pode sofrer e se perder em ambientes hostis ao seu florescimento:

Existe paixão pela compreensão, assim como pela música. Essa paixão é bastante comum em crianças, mas costuma se perder com o tempo. Sem ela, não haveria matemática nem ciências naturais (EINSTEIN. 2010, p. 12).

Ao dizer que "é quase um milagre que os métodos modernos de instrução não tenham exterminado completamente a sagrada sede de saber", Einstein considera que os espaços acadêmicos de sua época ameaçavam aquela paixão sem a qual não há espírito científico. Esse sentimento de curiosidade não pode ser controlado e todo direcionado para fins utilitários, nem restringido por um dia a dia de disciplina sufocante. É preciso deixá-lo livre e permitir-lhe a especulação pura. A educação utilitária está sempre presa ao aqui e agora, à solução de demandas práticas. No entanto, Videira nos lembra de que Einstein concebia a ciência como "uma possibilidade de escapar ao cotidiano, movendo-se em direção a uma transcendência" (VIDEIRA.2017, p. 16). Compreendia a ciência muito mais como vocação do que apenas como profissão. A ciência possuía uma dimensão sublime, capaz de nos elevar acima do cotidiano e das paixões pessoais (EINSTEIN. 1981, p. 138). $\mathrm{Na}$ maturidade Einstein trabalhou com Abraham Flexner em Princeton, que dirigiu o Instituto de Estudos Avançados. Em Princeton pode desfrutar de um ambiente compatível com suas concepções. A visão de Flexner sobre como deveria ser o espaço de ensino e pesquisa expressam muito bem o ideal nutrido por Einstein:

As instituições de ensino deveriam se dedicar ao cultivo da curiosidade. Quanto menos estiverem distraídas com considerações sobre aplicação imediata, tanto mais provavelmente contribuirão não só para o bem estar da humanidade, mas também para a satisfação igualmente importante da curiosidade especulativa (...) (FLEXNER Apud ORDINE. 2016, p. 182).

Einstein não pensa a educação universitária em separado da educação das crianças e dos jovens. Esse ambiente de liberdade e criatividade descrito por Flexner deveria abarcar todas as etapas do estudo, da escola à universidade. Perguntar "Qual é o valor da universidade para Einstein?" é questionar como ele concebia a educação de uma forma geral. A educação preservaria e desenvolveria a cultura, nos possibilitando, assim, uma transcendência. Para tanto, a educação não poderia ser instrumentalizada como uma forma de consumo:

Em várias outras ocasiões podemos percebê-lo enfatizando o papel duplo da educação na preservação e no desenvolvimento da cultura, vista por ele como uma construção coletiva e, em assim sendo, como um fruto dos valores máximos - éticos e artísticos - da civilização. Einstein, em outra ocasião, ao dirigir-se a jovens estudantes, identificou tal tratamento da cultura, com a própria imortalidade do ser humano, imortalidade do indivíduo calcada não só na apreensão, mas, também, no desenvolvimento do conhecimento produzido pelo coletivo (...). Einstein enfatizava, assim, a importância da educação como 
uma forma do ser humano transcender a sua própria finitude, de buscar na apropriação, preservação e desenvolvimento da cultura a sua própria imortalidade. Diferentemente da ideologia corrente de muitos jovens atualmente, do aprender como ato de consumo e sem o enfrentamento de dificuldades, Einstein via, sobretudo, nesse esforço intelectual e entusiasta do ser humano, a que ele se referiu, a fonte da sua própria transformação (MEDEIROS \& MEDEIROS. 2006, p. 188-189).

Motivado por razões variadas Einstein concebeu que o valor da ciência é sublime: elevar-nos acima do cotidiano e nos abrir para uma experiência de transcendência. E pensou que da escola à universidade o valor da educação não deveria estar condicionado ao utilitarismo prático e técnico - a educação deveria preservar, transmitir e aumentar a riqueza cultural legada por nossos antepassados, não se limitando a formar mão de obra para o mercado de trabalho, mas jovens críticos, livres e criativos, curiosos, sedentos por saber, que se deleitam com a beleza e o mistério do mundo, capazes de expandir os limites do conhecimento humano e de lutar por justiça social. A universidade, portanto, não poderia ser dirigida por uma ideologia utilitária, instrumental, pautada por demandas práticas e técnicas, tornando-se uma fábrica de especialistas:

Não basta ensinar ao homem uma especialidade. Porque se tornará assim uma máquina
utilizável, mas não uma personalidade. É necessário que adquira um sentimento, um sen-
so prático daquilo que vale a pena ser empreendido, daquilo que é belo, do que é moral-
mente correto. A não ser assim, ele se assemelhará, com seus conhecimentos profissionais,
mais a um cão ensinado do que a uma criatura harmoniosamente desenvolvida. Deve
aprender a compreender as motivações dos homens, suas quimeras e suas angústias para
determinar com exatidão seu lugar exato em relação a seus próximos e à comunidade. (...)
Os excessos do sistema de competição e de especialização prematura, sob o falacioso pre-
texto de eficácia, assassinam o espírito, impossibilitam qualquer vida cultural e chegam a
suprimir os progressos nas ciências do futuro. É preciso, enfim, tendo em vista a realização
de uma educação perfeita, desenvolver o espírito crítico na inteligência do jovem. Ora, a
sobrecarga do espírito pelo sistema de notas entrava e necessariamente transforma a pes-
quisa em superficialidade e falta de cultura. O ensino deveria ser assim: quem o receba o
recolha como um dom inestimável, mas nunca como uma obrigação penosa (EINSTEIN.
1981, p. 16).

As críticas de Einstein se dirigem tanto à ideia de que a educação deve formar especialistas quanto aos métodos disciplinares e coercitivos de tal sistema. $\mathrm{O}$ traço comum que une ciência e arte, que seria a superação do cotidiano e das paixões individuais, bem como o cultivo dos valores e de um espírito crítico livre, não poderia ocorrer em espaços dominados pela especialização e pelo rigor sufocante.

Em Por que os físicos acreditam que as coisas existem? Antonio Augusto Passos Videira nos apresenta um Einstein físico filósofo adepto de um "realismo harmônico", que busca a harmonia entre a teoria e o real, um "humanista e espinozista" que propõe a superação da cisão entre o homem e a natureza. Este Einstein não pode ser sobreposto ao de Galison, pois não é o jovem de Zurique ou Berna, mas o físico filósofo da maturidade. No entanto, elaboremos um gedankexperiment e imaginemos o velho Einstein tendo em mãos Os relógios de Einstein e lendo a descrição de Galison de como ele chegara aos resultados de 1905. Em nosso entendimento, esse Einstein não poderia concordar com Galison que o conceito de átomo, por exemplo, foi elaborado por analogia ao girocompasso, ou o conceito relativístico de simultaneidade por analogia ao relógio. Videira nos lembra de que para o físico filósofo "Os conceitos são uma livre criação do espírito" (VIDEIRA. 2017, p. 63). O próprio Einstein ao falar que o cientista não deve ter escrúpulos epistemológicos diz que os conceitos são livres criações do espírito "que não podem ser deduzidas logicamente do dado empírico". Parece-nos pouco plausível que Einstein reduzisse a ideia de "livre criação" ou "especulação pura" ao raciocínio analógico por influência do ambiente social; que aceitasse que os conceitos científicos e a teoria física fossem extrapolações, para representar os fenômenos naturais, dos projetos de engenharia das máquinas e instrumentos científicos. 
O espírito cria os conceitos, mas o fará por influência de fatores sociais cotidianos ou por especular livremente concebendo possibilidades que transcendem a experiência cotidiana e a vivência social? Além disso, também não nos parece crível que o Einstein da maturidade concordaria com Galison que o clima prático, utilitário, da Politécnica, teria contribuído para a formação do caráter necessário ao desenvolvimento de uma das teorias mais revolucionárias - e abstratas - da física, a relatividade restrita. Se assim fosse, Einstein teria de se compreender como devedor do senso de utilidade prática da ETH, e de reconhecer tal ambiente, e seus valores e métodos, como o mais adequado para a pesquisa científica em física teórica. No entanto, como Videira nos lembra, para Einstein, se um anjo expulsasse os maus cientistas do Templo da Ciência, expulsaria, dentre outros, "aqueles que veem a ciência apenas como algo que possui utilidade" (VIDEIRA. 2017, p. 71) ${ }^{4}$. Não nos parece que Einstein concebesse um clima universitário permeado pelo senso de utilidade prática como fecundo para o desenvolvimento do espírito crítico e criativo, e, portanto, da teoria física. Em verdade, pensamos que Einstein se insere em uma longa tradição de cientistas e filósofos que desde o século XIX perceberam e denunciaram o avanço do utilitarismo no ambiente universitário. Miguel e Videira nos lembram de que tal posicionamento se faz presente desde os primórdios da filosofia da ciência com William Whewell (MIGUEL; VIDEIRA. 2011, p. 41).

\section{Conclusão}

O Einstein de Galison teria sido influenciado pelo ambiente acadêmico da Politécnica. De fato, isso ocorreu. Não somente em suas práticas de ciência, como em sua concepção de educação. Tal influência, ao invés de ser positiva, o marcou negativamente de modo bastante significativo - aquele ambiente representava para ele a antítese do ideal de educação. Ao longo da vida, em inúmeras ocasiões, o físico filósofo enfatizaria o quanto o ambiente disciplinar, "penal”, utilitarista, é sufocante para o espírito, ameaçando a própria cultura e a ciência, formando "meros especialistas" ao invés de livres pensadores. O Einstein de Jammer, filósofo natural, metafísico, até mesmo teólogo, estaria bem mais alinhado com suas concepções sobre educação. Todavia, os exageros desta imagem também devem ser evitados. Se Galison supervaloriza a dimensão social, institucional, e minimiza os aspectos filosóficos e os compromissos teóricos, Jammer faz o contrário ao negar totalmente a dimensão social e política e frisar tão somente a filosofia, a metafísica, a especulação pura e o livre pensamento. Temos assim imagens opostas que nos oferecem possibilidades interessantes, mas perdem bastante em complexidade. Temos de escolher uma ou outra, sendo impossível conciliá-las. Nem tanto ao céu, nem tanto ao mar, escolhemos uma imagem de Einstein em que elementos filosóficos, metafísicos, psicológicos, sociais, políticos e culturais se combinem. Quanto mais complexa nossa abordagem, mais próxima do real; é no que acreditamos. Einstein seria sim influenciado por seu ambiente social, tanto quanto por suas ideias, crenças e ideais. Em sua biografia, tais dimensões estariam entrelaçadas, e se reforçariam mutuamente. Não há como separar o Einstein leitor dos filósofos, movido pelos ideais de "sede de saber" e "paixão por compreensão", do Einstein estudante da Politécnica, funcionário do Escritório de Patentes. Uma imagem mais complexa de Einstein pode ser fecunda para aqueles que desejam a uma resposta não utilitária para a questão "Qual é o valor da ciência e da universidade?". Abrangendo tanto a dimensão filosófica quanto a dimensão social, esse Einstein apresentaria uma imagem de ciência epistemicamente centrada e socialmente robusta, na qual a universidade é um centro de formação cultural capaz de nos insuflar as aspirações mais elevadas, um espaço de preservação e transmissão da cultura, bem como de sua expansão, que deve formar pessoas com espírito crítico e científico, compromissadas com a busca da verdade e a luta pelo bem social.

Em seu Manifesto da Filosofia Pau-Brasil, André Mendonça nos exorta a praticar filosofia ao invés de simplesmente reproduzir um comentarismo, que se restringe a analisar respostas consagradas, para problemas postos por terceiros, e sempre pelo viés da história da filosofia (MENDONÇA, 2017). Cesar Augusto Ramos em Aprender a filosofar ou aprender a filosofia: Kant ou Hegel? Busca resolver o impasse entre duas tendências em ensino de filosofia; por um lado, a ênfase kantiana no filosofar, por outro, a ideia hegeliana de que para aprender a filosofar é necessário instruir-se e conhecer o que os filósofos pensaram ao longo da

4 Tal imagem do "Templo da Ciência” faz parte do discurso comemorativo aos sessenta anos de Planck, proferido por Einstein. 
história (RAMOS, 2007). Cremos que os dois autores concordam nesse aspecto. Aprender com os filósofos é fundamental, mas não basta, é preciso ir além e filosofar. Nesse artigo buscamos trabalhar com essas duas perspectivas simultaneamente. Tínhamos um problema, e queríamos analisar, filosoficamente, como outros autores trataram dele. Ao longo do texto, à medida que analisamos o pensamento desses autores, buscamos estabelecer um diálogo crítico, filosófico, com eles, para construirmos, paulatinamente, nossa própria resposta. Talvez isso não seja, ainda, um filosofar pleno, ou uma Filosofia Pau-Brasil, em sentido forte, mas pode ter sido ao menos a tentativa de um primeiro passo. Esse passo se caracteriza, mais do que por um método, por uma atitude. Nossa atitude esteve permeada pelo desejo de não nos restringirmos a descrever as imagens de Einstein elaboradas por Peter Galison e Max Jammer, mas de criticarmos tais imagens naquilo que nos parecem insuficientes, e de indicarmos, ainda que de modo breve, como uma imagem mais complexa se faz necessária e como pode ser obtida.

A despeito de este artigo tratar de Einstein, ele não é sobre Einstein, mas sobre o (1) o modus operandi de parte dos estudos de ciência contemporâneos, a saber, da estratégia de revisitar a tradição, os grandes nomes da história da ciência, para, a partir de sua vida e obra, reforçar uma determinada imagem de ciência e (2) sobre as disputas epistemológicas e políticas entre as imagens assim elaboradas. Se nos interessa responder a questão "Qual é o valor da ciência e da universidade?" de um determinado modo, é bem mais fácil comentar as concepções de nomes como Poincaré, Planck, Einstein, Heisenberg, Schrödinger ou José Leite Lopes, ou, como no presente caso, Peter Galison e Max Jammer, do que oferecermos, nós mesmos, uma resposta. Este apelo à autoridade nos deixa em uma posição aparentemente cômoda e segura. Assim, nunca pensamos, nos limitando a comentar o que os outros pensaram. No Manifesto da Filosofia Pau-Brasil Mendonça considera que esse comentarismo marca uma atitude que se caracteriza pelo medo de filosofar e que se restringe a falar de filosofia (MENDONÇA. 2017, p. 118). Estamos de acordo com tal análise, e por isso ressaltamos que não devemos acatar uma imagem de ciência, de educação científica e de universidade (ou uma imagem de Einstein) sem antes nos perguntar quais os usos políticos e ideológicos que seus autores fazem de tal imagem, quais concepções de natureza e de natureza da ciência pretendem reforçar com elas.

Precisamos ressaltar, também, que se pretendemos fazer filosofia e não apenas comentar a filosofia que os outros fizeram, é preciso, em algum momento, deixar de responder as questões levantadas na terceira pessoa e passar a fazê-lo na primeira. Sendo assim, não haveria outra forma de concluir este artigo a não ser dizendo que nossa resposta para a questão do valor da ciência é que esta não pode ser presa do utilitarismo instrumentalista, seja neoliberal ou de qualquer outro tipo, não pode ser refém de projetos de poder e de interesses corporativos e estatais. A ciência possui elevado valor cultural, é uma forma de cultivo do espírito, ou seja, daquilo cujo valor é intangível e não meramente utilitário, mas a ciência deve ser também uma força de libertação dos povos, de promoção da justiça social e do bem comum. E a universidade, como espaço plural de formação intelectual e cidadã, é o melhor lugar para que a ciência, com tais valores, floresça. Deste modo, não pode a universidade tornar-se uma empresa, adotar um produtivismo improdutivo, uma espécie de fordismo acadêmico, ser manejada pelos interesses do mercado, protagonizar a comoditização da ciência e a formação em massa de especialistas. A universidade é aquele Templo da Ciência do qual nos fala Einstein. Temos de ir além; é o Templo da Cultura em suas mais variadas formas de expressão. Não é que a utilidade não seja bem-vinda, ela tem a sua função e sua importância, mas ela não pode ocupar o núcleo, não pode ser o coração da vida pulsante, não deve ter lugar privilegiado no altar da criatividade, da liberdade, da beleza, da "sede de saber" e da "paixão pela compreensão". 


\section{Referências}

BRIAN, Dennis. Einstein: A ciência da vida . Tradução de Vera Caputo. São Paulo: Editora Ática, 1998.

DAHMEN, Silvio Renato. Einstein e a Filosofia. Rev. Bras. Ensino Fís. v.28 n.1. São Paulo, 2006.

EINSTEIN, Albert. (Induction and deduction in physics). Sci. stud. vol.3 no.4 São Paulo Oct./Dec. 2005. Tradução do alemão, de A. M. Adam para o Journal for General Philosophy of Science, 31, p. 34-5, 2000.

. A Teoria da Relatividade Especial e Geral. Rio de Janeiro: Contraponto, 2012.

.Como eu vejo o mundo. Trad. H. P. de Andrade. Rio de Janeiro: Nova Fronteira, 1981.

Escritos da maturidade. Trad. Maria Luiza X. de A Borges. Rio de Janairo: Nova Fronteira, 1994.

. Notas autobiográficas. Rio de Janeiro: Nova Fronteira, 1982.

Sobre a teoria geral da gravitação: in Prêmios Nobel na Scientific American. São Paulo: Duetto, 2010.

EINSTEIN, A; INFELD, L. A Evolução da Física. Trad. Giasone Rebuá. Rio de Janeiro: Zahar Editores, 1980.

GALISON, P. Os relógios de Einstein e os mapas de Poincaré. Lisboa: Gradiva, 2005.

.Culturas etéreas e culturas materiais in A ciência tal qual se faz. Coord. Fernando Gil. Lisboa: Edições João Sá da Costa, 1999.

.The Disunity of Science. Standford: Stanford University Press. 1996.

HEISENBERG, Werner. A parte e o todo: encontros e conversas sobre física, filosofia, religião e política. Rio de Janeiro: Contraponto, 1996.

JAMMER, Max. Concepts of Mass in Modern Physics. Mineola: Dover Publications, Inc., 1997.

.Concepts of Space: The History of theories of Space in Physics. Mineola: Dover Publications, Inc., 1993.

.Einstein e a religião: Física e Teologia. Rio de Janeiro: Contraponto, 2011.

LORENTZ, Hendrik.Antoon; EINSTEIN, Albert; MINKOWSKI, Hermann. O princípio da relatividade. I vol. Lisboa: Fundação Calouste Gulbenkian, 2001.

MACH, Ernest. The Science of Mechanics. New York: The Open Court Publishing Co., 1974.

MAXWELL, James Clerk. Textos Selecionados. Antonio Augusto Passos Videira e Carlos Fils Puig (Org); Carlos Fil Puig (Trad.). Rio de Janeiro: Eduerj, 2017.

MENDONÇA, André Luis de Oliveira. Filosofia da Ciência e Science Studies: A guerra pela paz. In: VIDEIRA, Antonio Augusto Passos. (Org.). Perspectivas Contemporâneas em Filosofia da Ciência. Rio de Janeiro: Eduerj. 2012. p. 165-184.

MENDONÇA, André Luis de Oliveira. Manifesto da Filosofia Pau-Brasil: da Filosofia na Ágora à Filosofia de Agora. E de Volta para o 'Futuro Passado'!. Em Construção.

ano 1, n. 1, 2017, pp. 106-122.

MEDEIROS, André; MEDEIROS, Cleide Farias de. Einstein e a educação. São Paulo: Editora Livraria da Física, 2006.

MIGUEL, Lenardo Rogério; VIDEIRA, Antonio Augusto Passos. A distinção entre os "contextos" da descoberta e da justificação à luz da interação entre a unidade da ciência e a integridade do cientista: o exemplo de William Whewell. Revista Brasileira de História da Ciência, v. 4, n. 1, 2011.

NIINILUOTO, Ikka. Is Science Progressive? Dordrecht: D. Reidel Publishing Company, 1984.

NOVELO, Mario. Do Big Bang ao universo eterno. Rio de Janeiro: Jorge Zahar Ed., 2010.

ORDINE, Nuccio. A utilidade do Inútil - um manifesto. Luiz Carlos Bombassaro (Trad.). Rio de Janeiro: Zahar, 2016

PAIS, Abraham. Einstein viveu aqui. Trad. Carolina Alfaro. Rio de Janeiro: Nova Fronteira, 1997.

PAIS, Abraham. Sutil é o Senhor: a ciência e a vida de Albert Einstein. Rio de Janeiro: Nova Fronteira, 1995.

Philosophy of Science, 31, p. 34-5, 2000.

REIS, Verusca Moss Simões; VIDEIRA, Antonio Augusto Passos. John Ziman e a ciência pós-acadêmica: consensibilidade, consensualidade e confiabilidade. Scientiae Studia, São Paulo, v. 11, n. 3, p. 583-611, jan. 2013. 
RENN, Jürgen. A Física de cabeça para baixo: Como Einstein descobriu a teoria da relatividade especial. Rev. Bras. Ensino de Fís. v.27, n.1, p. 27-36. São Paulo, 2004.

SILVA, Vinícius Carvalho. Entre a pesquisa fundamental e a pesquisa aplicada: Qual o valor da Ciência?. Rio de Janeiro: ESOCITE, 2015. Disponível em: <http://www.rio2015.esocite.org/resources/anais/5/1442022400_ARQUIVO_ViniciusEntreapesquisafundamentaleapesquisaaplicadaQualovalordaCiencia.pdf>

SPINOZA, Baruch. ÉTICA. Trad. Lívio Xavier. São Paulo: Atena Editora, 1957.

VIDEIRA, Antonio Augusto Passos. Inevitabilidade da Filosofia na Ciência Natural do século 19. Ijuí: Editora Unijuí, 2013, p. 195).

Filosofia da Ciência sob o signo dos Science Studies Abstracta, v.2, n.1, pp. 70 - 83, 2005.

. Historiografia e História da Ciência in Escritos: Revista da Casa de Rui Barbosa. Ano 1, n.1. 2007.

. (Org). Perspectivas Contemporâneas em Filosofia da Ciência. Rio de Janeiro: eduerj. 2012.

. Por que os físicos acreditam que as coisas existem? Breves comentários a respeito das relações entre ciência e metafísica. Braga: Axioma, 2017. 